\title{
KEYNOTE: Three Positive Outcome TA Psychotherapy Cases: Hermeneutic Single-Case Efficacy Design Research in Action
}

C 2012 Mark Widdowson

\section{Introduction}

The background to the research I have been involved in was my frustration with the dominance of CBT within statutory therapy services within the UK and a continued lack of recognition for TA. To me, as to most TA therapists, I could see in my day to day practice that TA was indeed an effective approach, but was afraid that that unless we as a community start to quickly accumulate research evidence supporting our convictions that TA would continue to be marginalised. As a result of an informal conversation with Professor John McLeod- a respected counselling and psychotherapy researcher-I was inspired to engage in research and to enrol with the University of Leicester to begin a PhD investigating the process and outcome of TA psychotherapy. I am now four years into my doctoral research, and have found it to be a deeply enriching experience which has brought me a great deal of personal and professional satisfaction. As my research has developed, I have become clearer in my vision and aim. My vision is to see TA recognised as an EmpiricallySupported Therapy by the year 2020. This is an entirely realistic vision, and I hope that in reading this that many of you will be encouraged to join in and make this vision a reality.

At this point, it is perhaps worth exploring a little bit about what research means to many within our community. My sense is that many of you will be able to identify with the following statement;

'I know research is important... to help us to understand how therapy works, to improve how we do therapy, to contribute to our profession and to promote wider acceptance of TA and psychotherapy'

Is this true for you? I also suspect that many of you will be able to identify with the following statement;

'My negative impression of research is that it... Isn't for people like me, it is complex, boring and time consuming, it is not relevant to the practice of therapy and is an ethically dubious activity

Is this statement true for you also? I would imagine that many of you will be able to identify with much of the second statement. I am basing my speculation about your views of research on some recent research which I conducted which investigated the perceptions that 16 TA psychotherapy trainees had of psychotherapy research. (for more information on the results of this research, see; Widdowson, M. (2012a).

As I see it, if this second statement is common amongst members of the TA community, then unless this is addressed, the vision I described above will not become a reality. It is part of my intention in writing this article to highlight that research does not need to be complex, boring or time consuming, can be conducted by people like you and can produce findings which are highly relevant and applicable to the realities of the consulting room.

\section{Types of Psychotherapy Research}

Essentially, psychotherapy research falls into two main categories; Outcome Research which investigates the efficacy or effectiveness of a particular therapy and Process Research, which investigates issues such as what actually happened in the therapy or what were the key factors which produced change. In the case series I describe below, I attempted to investigate both the outcome and process of TA psychotherapy with clients who had depression.

A common criticism of psychotherapy research is that too often it appears to be irrelevant or too far removed from the realities of clinical practice. Indeed, even as a psychotherapy researcher, I often come across research articles which may be interesting and well-designed but which do not appear to me to have any direct or easily applicable relation to the work I might do with my clients.

'Although a series of well-designed studies might establish the efficacy of an intervention, unless it is effective in real-life clinical settings, it will not be useful' (Nathan, Stuart and Dolan, 2000: 974)

A challenge for me in designing the research was to examine how it would be possible to conduct welldesigned research which demonstrated the effectiveness/ efficacy of TA and which would generate findings which are relevant to and easily transferred into routine clinical practice. Furthermore, I wanted to use a 
research method which is accessible enough that it can be replicated easily, one which draws on the skills which we already have within the TA community and is both rigorous and scientific.

\section{Systematic case study research - an answer to the challenge?}

At the suggestion of my research supervisors, Professors Sue Wheeler and John McLeod, I decided to conduct my research as a case series, primarily using Hermeneutic Single-Case Efficacy Design (HSCED) (Elliott, 2011, 2002) for the data analysis. HSCED is a mixed-methods research approach (one which uses both quantitative and qualitative data) and is based on a detailed case study which accounts for the unique features of the case. A unique feature of HSCED is the use of a quasilegal method of cross-examination of data and independent adjudication to determine the conclusions in each case regarding outcome factors such as whether the client changed substantially over the course of therapy and whether that change was due to the effects of therapy. Process aspects are also investigated by considering factors associated with the therapy or therapist and client factors which contributed towards the change (for more information, see Widdowson, 2011, 2012b, 2012c, 2012d)

\section{Summary of the case series}

All of the clients in the cases summarised here had 16 sessions of individual TA psychotherapy with therapists working in private practice. It is important to consider this context when evaluating both the findings and the factors which the judges concluded were relevant in facilitating change. The full research article of each of these three cases can be downloaded from the IJTAR website www.ijtar.org . A brief summary is provided here, although I would recommend you to read the full article for each case to get a clear sense of the process and the findings of the research.

\section{Case One- 'Peter'}

Peter was a 28 year-old, unemployed and somewhat socially isolated British male with severe depression. He had been bullied throughout school and his mother died when he was 13. He had some awareness that he was holding onto some repressed emotions and felt that these were driving his depression. He was an intelligent, articulate and psychologically-minded young man. At the outset of therapy he had severe depression and moderate global distress and functional impairment. By the end of therapy he was demonstrating clinically significant change on two of the three outcome measures used and reliable change on the third. His improvements were maintained at the one month and six-month follow up periods and in post-therapy interview he identified five changes which were important to him and which he felt unlikely to have come about without therapy. The judges who adjudicated the case concluded that Peter had experienced clinically significant changes although had not fully resolved all his problems, and that these changes were substantially due to therapy. The verdict of the judges was that this was a good outcome case with client changing considerably-substantially and these changes were substantially due to therapy.

The judges also considered the therapy process and concluded that the aspects of the therapy which were helpful included Peter's experience of the therapist as empathic, genuine, honest, accepting and caring, and the therapist's emotional engagement with Peter. It was also considered important that the therapist had used and shared TA theory when relevant with Peter had been helpful. Factors which were associated with Peter (as opposed to the therapy or therapist) which were considered helpful were his commitment to the therapy process and apparent determination to overcome his initial discomfort, his level of motivation for change, his belief in the effectiveness of therapy (hope) and the close match of therapist and type of therapy with his preferences.

\section{Case Two- 'Denise'}

Denise was a 46 year old, white, British social worker with severe depression. She had had some previous therapy and some counselling skills training and so was well-informed about therapy and had a clear sense of what to expect from the therapy process. Denise was unhappy at work, and also finding the many demands placed on her by her family to be difficult to manage. At the point of entry into therapy she had severe depression and was experiencing moderate global distress and functional impairment. At the end of therapy she had achieved clinically significant change on two outcome measures and reliable change on the third. She also continued to improve throughout the 6 month follow-up period. In her post-therapy interview, she identified ten changes which were 'extremely' important to her and which she felt unlikely to have come about without therapy. The unanimous verdict of the judges was that the case had a clearly good outcome, that Denise had changed substantially and that this had substantially been due to therapy. The judges concluded that the empathic, non-judgmental and encouraging stance of the therapist had been important in this case, as was the therapist's willingness to use TA theory to provide a rationale for the therapy and to help Denise in making sense of her experiences and process. It was also considered that the therapist's continued challenging of Denise's script, their attentiveness to how it might be manifesting in the therapy and avoidance of reinforcing her script had also been a significant factor.

Additionally, Denise's sense of hopefulness at the outset of therapy and the fact that she was well-informed about therapy and TA and so made an informed decision in choosing the right therapist was considered to have been important. Other important factors included the fact that Denise was clearly well-motivated, had clear goals for the therapy and a degree of insight from the outset. Furthermore, her courageousness and willingness to address difficult and painful material and her continued attempts to integrate the insights gained in therapy into her everyday life were all identified as additional key factors in the change process. 
Case Three- 'Tom'

Tom was a 38 year-old, white, male builder with mild depression and social anxiety. Tom had experienced very harsh parenting which had left him feeling 'stupid' and 'useless' and with a strong self-critical process. Prior to entering therapy, he had become very interested in TA and had read several books about TA and had been active in use of TA-based self-help strategies. At the point of entry into therapy he had moderate depression with mild global distress and functional impairment. Tom achieved clinically significant change on all outcome measures by session 8 which was maintained at end of therapy and up to the three-month follow-up period although he did show some decline at the 6 month follow-up. In his post-therapy interview he identified eight changes which were 'extremely' important to him and which he felt unlikely to have come about without therapy. The judges' majority verdict was that this was also a good outcome case and that Tom had changed substantially and that this had substantially been due to therapy. The judges concludes that the empathic, non-judgmental and highly active approach of the therapist had been important in this case and that the use of two-chair methods had been highly effective at helping Tom to overcome his selfcritical process, express emotions and re-evaluate his perspectives. Furthermore, it was considered that Tom greatly benefitted from developing practical strategies for improving communication and from the use of TA concepts to help him understand his process. The judges also identified that Tom's pre-therapy reading, his level of motivation readiness to change and his willingness to engage with painful emotions and experiences and actively make use of the therapy were all also important factors in his change process.

\section{So, what is the conclusion so far?}

Using criteria defined by Chambless and Hollon (1998), it is possible from the findings of these three cases to put forward a claim that TA therapy is Possibly Efficacious for the treatment of depression, and TA now meets basic criteria for consideration for 'Empirically Supported Therapy' status for the treatment of depression. This is a wonderful result for the TA community, although the key to ensuring that we gain the recognition which we feel we deserve is through replication of research. It is perhaps clear from this that we do not need to conduct large-scale Randomised Controlled Trials to gain recognition, and that with further positive replication of research we can meet criteria to have TA recognised as Demonstrably Efficacious and as an Empirically Supported Therapy.

It is my view that the resources of the TA community can be most effectively used by many researchers or research groups focusing on gathering evidence for the effectiveness of TA therapy in one specific clinical area. My recommendation is that for maximum strategic impact we focus in the short-term on depression, moving into other clinical areas in a systematic way over the coming years. It is perhaps worth saying here that the 'active phase' of my research, including the analysis of the cases took place over a period of 18 months, so if over the next three years we see a focus on depression, we can secure our position and gain wider recognition, and then broaden our research horizons to gain evidence for the effectiveness of TA for other clinical areas.

\section{Ideas for Research Projects}

As stated above, I propose that we focus initially on research investigating the outcome of TA therapy for depression. As a starting point, I make the following suggestions. I am happy to discuss any of these with those who may be interested in taking these ideas forward.

- Two small studies involving at least three cases each which replicate my procedures for people with depression

- A series of single systematic case studies of TA therapy for depression

- My research protocol is available if you want to replicate the procedures in my research!

- A large sample group (minimum 20 clients) measures at pre-therapy and post- therapy (plus follow-up) of impact of TA therapy as measured using several outcome measures, including one measuring depressive symptoms (note: a Practice Research Network would quickly accumulate this data)

- TA therapy for post-partum/ perinatal depression (can be small-scale project e.g. 3-6 cases)

- TA therapy for depressed older adults (can be small-scale project e.g. 3-6 cases)

- TA therapy for depressed adolescents (can be small-scale project e.g .3-6 cases)

- $\quad$ TA therapy (short term) for students (over 18 years) with depression/ depressive symptoms

- TA therapy for depression with (specific medical condition) (can be small-scale project e.g. 3-6 cases)

- TA counselling for carers and impact on self-esteem and depressive symptoms

- TA group therapy for depression

- TA psychoeducational group for depression (with or without waiting-list control group)

- TA psychoeducational group for sub-threshold depression (measuring impact on PHQ-9 scores, CORE scores and self-esteem scores) (with or without waiting list control group)

- TA Couples therapy for depression (can be smallscale project e.g 1-3 'couple cases')

- TA therapy for depression with non-caucasian groups- both within and outside 'Western' countries

- TA therapy for depression with adult survivors of abuse (or other demographic)

- The effect of 'maintenance' therapy on reducing relapse or reduction in residual symptoms 
- A two-site study (with a small number of clients) investigating TA therapy for depression and having two different frequencies of supervision (for example weekly versus monthly)

- A study investigating effectiveness of trainee TA therapists (again, only a small number of clients needed)

- A study comparing outcome of TA psychotherapy with another therapy, or with medication or 'waiting list group' or control group

- A series of small-scale qualitative studies (3-6 clients, perhaps) which investigate what aspects of TA therapy clients with depression have found to be helpful (and also unhelpful factors)

- A qualitative study in which clients describe the changes they experienced as a result of TA therapy

\section{References:}

Chambless, D.L. and Hollon, S.D. (1998) 'Defining Empirically Supported Therapies.' Journal of Consulting and Clinical Psychology, 66(1): 7-18.

Elliott, R. (2001). Hermeneutic single case efficacy design (HSCED): An overview. In K.J. Schneider, J.F.T. Bugental \& J.F. Fraser (eds.), Handbook of Humanistic Psychology (pp315-324), Thousand Oaks, CA: Sage.
Elliott, R. (2002) 'Hermeneutic Single-Case Efficacy Design'. Psychotherapy Research, 12(1): 1-21

Nathan, P.E., Stuart, S., \& Dolan, S.L. (2000) 'Research on psychotherapy efficacy and effectiveness: Between Scylla and Charybdis?' Psychological Bulletin, 126: 964-981.

Widdowson, M. (2011) 'Case Study Research Methodology.' International Journal of Transactional Analysis Research, 2(1): 25-34.

Widdowson, M. (2012a) 'Perceptions of Psychotherapy Trainees of Psychotherapy Research.' Counselling and Psychotherapy Research, 12(3): 178-186.

Widdowson, M. (2012b) 'TA Treatment of Depression - A Hermeneutic Single-Case Efficacy Design Study - "Peter".' International Journal of Transactional Analysis Research, 3(1): 3-13.

Widdowson, M. (2012c) 'TA Treatment of Depression - A Hermeneutic Single-Case Efficacy Design Study - "Denise".' International Journal of Transactional Analysis Research, 3(2): $3-14$

Widdowson, M. (2012d) 'TA Treatment of Depression - A Hermeneutic Single-Case Efficacy Design Study - "Tom".' International Journal of Transactional Analysis Research, 3(2): 15-27. 